\title{
The Thule episode epidemiological follow up after the crash of a B-52 bomber in Greenland: registry linkage, mortality, hospital admissions
}

Knud Juel

\begin{abstract}
Study objective-The aim was to explore the pattern of disease in staff associated with a bomber that crashed in 1968 when carrying nuclear bombs.

Design-The database was constructed from staff files of Danish workers employed from 1 April 1963 to 1 July 1971. Comparison was made between subsequent mortality and hospital admissions of workers employed during the clean up of the crashed bomber, and those employed outside this period.

Setting-The study involved workers employed at Thule US air base in Greenland.
\end{abstract}

Main results-During 1963-1971, 4322 staff were employed at the air base. Of these, $4265(98.7 \%)$ were identified in 1987, among whom 1202 workers were employed during the clean up period. No differences were found in total mortality, or mortality from cancer, heart disease, or accidents, after allowing for differences in age, marital status, or length of employment, between those employed during the clean up period and those employed at other times. Similarly, no difference in hospital admissions between the two groups was found.

Conclusions-No harmful effects on health due to the crash were found, as measured by mortality and hospital admissions.

f Epidemiol Community Health 1992; 46: 336-339

On 21 January 1968, a US B-52 bomber crashed on sea ice approximately $12 \mathrm{~km}$ west of the US radar base at Thule in northwest Greenland. The bomber carried four nuclear bombs, and, following an explosion their contents, ie, plutonium, americium, and tritium, were spread over the sea ice and sea near the crash site. ${ }^{1}$

Since 1986, there has been a widespread debate on the Thule episode in the Danish media and several questions on the event have been posed in the Danish Parliament. Compensation to the Thule workers for work related injuries was an important issue in the debate. US lawyers were engaged to conduct cases for some of the Thule workers, and these lawyers have talked about damages amounting to $\$ U S 100000$ per worker.

The diseases and symptoms that have been mentioned affect most organ systems; in addition, general symptoms such as fatigue, somnolence, weight loss, and premature aging have been reported. ${ }^{2}{ }^{3}$ There seems to be no clear pattern of disease but skin diseases have been mentioned frequently. ${ }^{4}$ Many of the spokesmen have stressed that in order to elucidate possible damage to health due to the crash it is not sufficient to look merely at cancer cases.

Contact with radioactive material may have taken place within the areas where contamination was demonstrated, ie, within a controlled area on the ice and on the so called "tank farm" near the base, where the contaminated snow and ice were loaded into fuel tanks. Exposure may also have occurred in connection with the repair, servicing, and refuelling of vehicles and machinery used in connection with the clean up operation. The possibility that exposure also occurred owing to the spread of radioactive material outside the contaminated areas must be considered. The most likely possibility is airborne contamination immediately after the accident, and perhaps also due to two arctic storms that occurred on 24 and 27 January, and in connection with the transport of snow and ice to and through the base area. Many persons have recounted that the containers in which the contaminated snow was to be collected were leaky. The possibility of indoor spread of radioactivity through the ventilation system has also been mentioned. Finally, indirect exposure through local ecosystems must be taken into consideration.

When nuclear radiation is suspected, the immediate reaction is to look for cases of cancer. ${ }^{56}$ However, knowledge about the construction, components, and possible cargo of a military bomber is very limited, and the possibility of the presence of unknown and potentially harmful substances must be taken into account.

This paper gives an account of the construction of a database on the Thule workers and assesses the validity of the information it contains. Mortality and hospital admissions were compared in two groups of Thule workers: a study group of possibly exposed workers and a reference group of non-exposed workers.

\section{Methods}

Between 1 April 1963 and 1 July 1971, the Danish Construction Corporation (DCC) was responsible for the employment of Danish workers on the Thule base in Greenland. The staff file from that period forms the basis of this investigation.

The file includes name, date of birth, address, marital status, and dates of departure from and arrival at Copenhagen for each employment period on the base. From this information, we tried to identify the workers to establish whether 
they were alive, had emigrated, or had died. Personal identification numbers were introduced in Denmark on 1 April 1968, and after that date all Danes have such a unique identification number. By linking information from the staff file with information from the register of personal identification numbers, local municipality registers and other sources, a total of $\mathbf{4 2 6 5}$ persons $(\mathbf{9 8 . 7} \%$ ) were identified.

Both the General Workers' Union in Denmark and the Danish National Board of Health had information of about 300 persons who had been on the base during 1968. All those who claimed to have been engaged by the DCC were found in the staff file.

The causes of death were obtained from the computerised register of causes of death at the Danish Institute for Clinical Epidemiology. This includes information on all deaths since 1943 based on death certificates in the Danish National Board of Health. Mortality was analysed from 9 September 1971, when the remaining DCC workers ended work, to 30 June 1986

The Danish National Patient Register includes records from all hospitals of contacts between stationary patients and the hospital services. Patients in mental institutions or in mental wards are not included. The register was established in 1977, and we have analysed discharges during the period 1977-1985.

The study group was defined as persons who had worked on the Thule base during the clean up period from the crash on 21 January 1968 to 17 September 1968, when the last of the contaminated material is stated to have been removed. The reference group consisted of persons employed during the period 1963-1971 but outside the clean up period (figure).

In the analysis of mortality and hospital admissions, we wanted to determine the differences in rates between the study group and the reference group and used a multiple logistic regression analysis. Age, marital status, and duration of employment were adjusted for. Age at first DCC employment was coded in three categories: $\leqslant 24$, $25-34$, and $\geqslant 35$ years. Age on 9 September 1971 (1 January 1977 for hospital admissions) was coded in the same categories. Marital status at first employment on the base was coded in four groups: married, unmarried, previously married, and no information. Seniority in years on the base was coded in four groups: $<1,1-2,2-3$, and $\geqslant 3$. The number of employment periods was coded in five groups: $1,2,3,4-5, \geqslant 6$. The study group was compared to the reference group using two variables: the first was whether the person was employed for the first time before the crash (yes/no), and the other was whether the person had been employed during the clean up period (yes/no); it is then possible to compare the four employment categories shown in the figure.

\section{Results}

At the time of first employment, $80 \%$ of Thule workers were under 35 years of age, and only $5 \%$ were more than 45 years of age. The age distribution was the same in the study group and in the reference group. Fifty eight per cent of the entire group were unmarried at first employment, $28 \%$ were married, $10 \%$ were either divorced or separated, and no information was found for $3.5 \%$. The study group included a few more unmarried and fewer married persons. With respect to length of employment, however, a large discrepancy was found between the two groups of workers (table I). The same difference is found for the number of employment periods.

Four hundred deaths occurred from the time of first employment up to 1 July 1986 . Twenty one per cent were coded as cancer, $28 \%$ as diseases of the circulatory system, $22 \%$ as other natural causes, and $23 \%$ as accidents, suicides, and violence. No information on cause of death from a Danish death certificate was found for 28 deaths; 23 of these had occurred abroad. Twenty four of the 400 deaths occurred before the crash, and 23 occurred from the crash up to 9 September 1971, when all workers engaged by the DCC had ended their work at the base. Of these 23 deaths only five were from the study group: three different cancers (oesophagus, lung, and skin melanoma), one suicide, and one death abroad without a death certificate.

|clean up period

Examples of employment periods of the study group (a) and (c) and of the reference group (b) and (d). (a) = Employed before and during the clean up period $(n=1088) ;(b)=$ employed before and not during the clean up period $(n=2406) ;(c)=$ not employed before but employed during the clean up period $(n=114)$; $(d)=$ not employed before or during the clean up period $(n=714)$

The multivariate analysis, which begins on 9 September 1971, thus included 353 deaths. Cause of death was not established for 23 of the 353 deaths, but these deaths were evenly distributed in the study group and the reference group. There were no differences in mortality from all causes and no significant differences for all cancers, lung cancer, diseases of the circulatory system, and other natural causes (table II). For accidents, suicides, and violence, and for suicide alone, there was a significantly lower mortality in the study group. There were no deaths from leukaemia.

On 1 January 1977, 3993 workers were alive and living in Denmark. Of these, 1886 had been in hospital at least once between 1977 and 1985. The risk of being admitted to hospital was the same in the two groups after adjusting for the variables included in the analysis (table III). A similar analysis was carried out for 16 disease groups. Of the 112 cancers there were 28 cancers of the lung $(\mathrm{OR}=1 \cdot 7,95 \%$ CI 0.8-3.7). No leukaemia was found in the study group.

\section{Discussion}

It is important to define the group that could have been exposed to contaminated material. We know for certain that up to 130 Danish workers 
were engaged in the special clean up work that took place in March 1968. This group has previously been studied with regard to occurrence of cancer $^{8}$ and death ${ }^{9}$ without finding any differences in comparison with the Danish population. Measurements of plutonium in the urine of 62 workers who had been engaged in the clean up operation or had been employed during or around the clean up period have been carried out. ${ }^{10}$ No plutonium was demonstrated in any of the urine samples, at a detection level of $200 \mu \mathrm{Bq}$ ${ }^{239}$ plutonium per sample.

Several people have argued that the group of 130 people was too narrowly defined. If the contamination had been widespread then workers employed only after the clean up period might also have been exposed (group $d$ in the figure). But in the analysis no difference was found between the four groups indicated in the figure, in other words group b, of which $97 \%$ of the workers had only been employed before the clean up period-an almost definitely unexposed group,

Table I Total length of employment on Thule Air Base 1963-1971 in the study and reference groups

Table II Odds ratio $(O R)^{2}$ for dying from selected causes of death among workers in the study group compared to workers in the reference group; period of analysis: 09.09.1971-30.06.1986

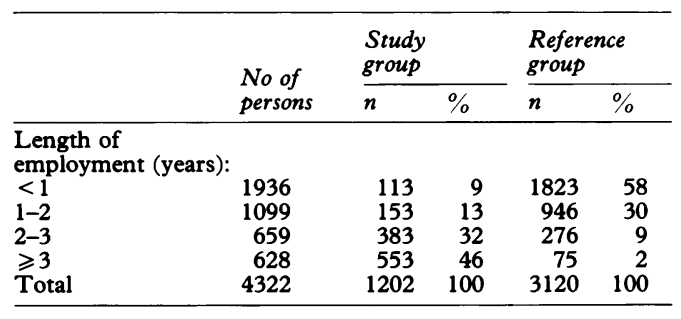

\begin{tabular}{|c|c|c|c|}
\hline Cause of death $\left(I C D^{\mathrm{b}}\right)$ & $\begin{array}{l}\text { No of } \\
\text { deaths }\end{array}$ & $O R$ & $(95 \% C I)$ \\
\hline All causes (001-998) & 353 & 0.8 & $(0 \cdot 6-1 \cdot 1)$ \\
\hline $\begin{array}{l}\text { All cancers }(140-209) \\
\text { Lung cancer }(162)\end{array}$ & $\begin{array}{l}73 \\
28\end{array}$ & $\begin{array}{l}1 \cdot 1 \\
0.8\end{array}$ & $\begin{array}{l}(0 \cdot 6-1 \cdot 8) \\
(0 \cdot 3-2 \cdot 0)\end{array}$ \\
\hline $\begin{array}{l}\text { Diseases of the circulatory } \\
\text { system }(390-458)\end{array}$ & 105 & 0.7 & $(0 \cdot 5-1 \cdot 2)$ \\
\hline Other natural causes ${ }^{c}$ & 83 & $1 \cdot 1$ & $(0 \cdot 7-1 \cdot 6)$ \\
\hline $\begin{array}{l}\text { Accidents, suicide and } \\
\text { violence (E800-E998) } \\
\text { Suicide (E950-E959) }\end{array}$ & $\begin{array}{l}69 \\
41\end{array}$ & $\begin{array}{l}0 \cdot 4 \\
0 \cdot 3\end{array}$ & $\begin{array}{l}(0 \cdot 2-0 \cdot 9) \\
(0 \cdot 1-0.8)\end{array}$ \\
\hline Unknown & 23 & & \\
\hline
\end{tabular}

Table III Odds ratio $(O R)^{\mathrm{a}}$ of hospital admission for selected disease groups among workers in the study group compared to those in the reference group. Both main and subdiagnoses are included

\begin{tabular}{|c|c|c|c|c|}
\hline Discharge diagnosis & $I C D^{\mathrm{b}}$ & $\begin{array}{l}\text { No of } \\
\text { persons }\end{array}$ & $O R$ & $(95 \% C I)$ \\
\hline All causes & & 1886 & $1 \cdot 0$ & $(0 \cdot 8-1 \cdot 1)$ \\
\hline $\begin{array}{l}\text { Infectious and parasitic diseases } \\
\text { Neoplasms } \\
\text { Benign neoplasms } \\
\text { Diseases of the endocrine system } \\
\text { Diseases of the blood and blood }\end{array}$ & $\begin{array}{l}000-136 \\
140-209 \\
210-239 \\
240-279\end{array}$ & $\begin{array}{r}82 \\
112 \\
86 \\
139\end{array}$ & $\begin{array}{l}1 \cdot 1 \\
1 \cdot 4 \\
1 \cdot 2 \\
1 \cdot 0\end{array}$ & $\begin{array}{l}(0 \cdot 7-1 \cdot 7) \\
(0 \cdot 9-2 \cdot 1) \\
(0 \cdot 7-1 \cdot 8) \\
(0 \cdot 7-1 \cdot 5)\end{array}$ \\
\hline $\begin{array}{l}\text { Diseases of the blood and blood } \\
\text { forming organs } \\
\text { Mental disorders }\end{array}$ & $\begin{array}{l}280-289 \\
290-315\end{array}$ & $\begin{array}{r}24 \\
227\end{array}$ & $\begin{array}{l}1.8 \\
1.7\end{array}$ & $\begin{array}{l}(0 \cdot 8-4 \cdot 1) \\
(1 \cdot 1-2 \cdot 5)\end{array}$ \\
\hline $\begin{array}{l}\text { Diseases of the nervous and sensory } \\
\text { system } \\
\text { Diseases of the circulatory system } \\
\text { Diseases of the respiratory system } \\
\text { Diseases of the digestive system } \\
\text { Diseases of the genitourinary system } \\
\end{array}$ & $\begin{array}{l}320-389 \\
390-458 \\
460-519 \\
520-577 \\
580-679\end{array}$ & $\begin{array}{l}187 \\
498 \\
229 \\
480 \\
206\end{array}$ & $\begin{array}{l}1.0 \\
1 \cdot 1 \\
1 \cdot 1 \\
1 \cdot 0 \\
1 \cdot 0\end{array}$ & $\begin{array}{l}(0 \cdot 7-1 \cdot 3) \\
(0 \cdot 8-1 \cdot 5) \\
(0 \cdot 8-1 \cdot 4) \\
(0 \cdot 8-1 \cdot 2) \\
(0 \cdot 7-1 \cdot 3)\end{array}$ \\
\hline $\begin{array}{l}\text { Diseases of the skin and subcutaneous } \\
\text { tissue }\end{array}$ & $680-709$ & 107 & 0.8 & $(0 \cdot 5-1 \cdot 3)$ \\
\hline $\begin{array}{l}\text { Diseases of the bones and organs of } \\
\text { movement } \\
\text { Congenital malformations } \\
\text { Symptoms and ill defined conditions } \\
\text { Accidents, suicide, and violence }\end{array}$ & $\begin{array}{l}710-738 \\
740-759 \\
780-796 \\
\text { E800-E999 }\end{array}$ & $\begin{array}{r}310 \\
33 \\
286 \\
621\end{array}$ & $\begin{array}{l}0.9 \\
0.9 \\
1 \cdot 0 \\
1 \cdot 1\end{array}$ & $\begin{array}{l}(0 \cdot 7-1 \cdot 2) \\
(0 \cdot 4-2 \cdot 0) \\
(0 \cdot 8-1 \cdot 3) \\
(0 \cdot 8-1 \cdot 4)\end{array}$ \\
\hline
\end{tabular}

${ }^{a}$ Calculated using the BMDP PLR program

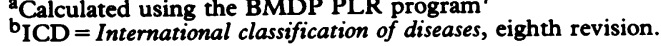

had the same mortality and hospital admission rate as the other groups.

The symptoms under suspicion cover a very wide spectrum. Total mortality is a well defined but also a very rough measure. If an exposure is non-lethal or very weak or perhaps affects only very few people mortality analyses of larger groups will give a negative result. However, one of the aims of this study was to invalidate or confirm the assertions of very high mortality due to the crash reported in the media. Cancer morbidity and mortality is also well defined and is a good measure, since cancer is often related to exposure to nuclear radiation. A broader measure of morbidity is hospital admissions, which are analysed here for the period 1977-1985. Both the cause of death register and the hospital register are assumed to be almost complete. The uncertainty is larger when analysing on the level of a diagnosis.

We consider that the problem of information bias is negligible. The staff file at our disposal appears to be of high quality, as we identified $98.7 \%$ of the 4322 workers. The Thule episode, however, is political dynamite, involving Greenpeace and the Danish Movement on Energy and Environment on one side and the North Atlantic Treaty Organisation and the US arms industry on the other. It was therefore important to establish whether some of the cards in the staff file could have been removed, since the present investigation would have been pointless if, for example, cards on exposed victims were missing. However, we found nothing to indicate that this has been the case. We also consider that there was no differential quality in the diagnoses in the two groups.

In comparing mortality and hospital admissions between the two groups, we tried to overcome the problem of confounding by performing a multivariate statistical analysis, adjusting for differences in age, marital status, and most importantly length of employment.

The Thule workers cannot be regarded as a random sample of the Danish population, or even of the Danish working population. Only men were employed on the base, who may have been independent of their families and may have gone to Greenland to earn quick money or for adventure. We therefore defined the reference group as other employees on the base during the period 1963-1971, who were not active during the clean up period.

The main conclusions from the study are that the quality of the file appears to be high and with the above mentioned reservations the register studies of mortality and hospital admissions show that no harmful effect on health due to the accident at the Thule base can be established with certainty.

1 Hunziker RO, ed. Project Crested Ice. USAF Nuclear Safety 1970; 65 (1).

2 OOA analyser. Thule 1968: Plutonium, Denmark 1986 Illness. Copenhagen: The Danish Movement on Energy and the Environment, 1986 (in Danish).

3 Greenpeace and OOA. The Thule accident 1968 Copenhagen: Greenpeace Books and Records, 1987 (in Danish).

4 Zachariae H, Søgaard H. Plutonium-induced mycosis fungoides and parapsoriasis en plaques-a new entity? In Vloten WA var, Willemze R, Lange Vejlsgaard G, et al, eds. Cutaneous lymphoma. Current Problems in Dermatology, vol 19. Basel: Karger, 1990: 81-9. 
5 Wilkinson GS, Tietjen GL, Wiggs LD, et al. Mortality among plutonium and other radiation workers at plutonium weapons facility. Am $\mathcal{f}$ Epidemiol 1987 ; 125 : 231-50.

6 Checkoway H, Pearce N, Crawford-Brown DJ, et al. Radiation doses and cause-specific mortality among workers at a nuclear materials fabrication plant. $\mathrm{Am} \mathscr{f}$ Epidemiol 1988; 127: 255-66.

7 Dixon WJ, ed. BMDP Statistical Software. Los Angeles: University of California Press, 1985.
8 Storm HH. Cancer amongst Danish workers engaged in cleaning radioactive pollution in Thule, Greenland in
1968.Ugeskr Lager 1987; 149: 1218-20 (in Danish with 1968. Ugeskr Lager

9 Juel K. Mortality

Juel K. Mortality and hospitalization among Danish employees at Thule Air-Base 1963-71. Copenhagen: The Danish Institute for Clinical Epidemiology, 1987 (in Danish).

10 National Institute of Radiation Hygiene. Plutonium analysis of urine among Thule workers. Copenhagen: National Board of Health, 1988 (in Danish).
Extract from Dr Ferriar's Advice to the Labouring Classes in Manchester; given in 1800

Some earlier pollution problems
The first extract shows that sea-coal was in use in London much earlier than is commonly supposed:-

"Patent Roll, 16 Edw. I-The king to his beloved and faithful Thomas de Weylaund, John de Luvetot, John de Cobeham, and Ralph de Sandwico, custos of his city of London, greeting: From the complaint of many persons, we understand that many people are dangerously aggrieved by the furnaces of lime which are built in the said city and its suburbs, and in Southwark; because the lime which formerly used to be burnt with wood, is now burnt with sea-coal, by which the air there is affected and corrupted, to the great danger of persons frequenting those parts and dwelling around them: we therefore, being willing to afford a fitting remedy for this, have appointed you to see those furnaces, and remove the danger and nuisances which threaten from them in these days, and to order further concerning them according to your discretion, as you shall see most expedient for the common use and safety; and therefore we commnad you, that taking with you our sheriffs of London and our bailiffs of Southwark, you perform the premises with diligence. We have also commanded the same sheriffs and bailiffs that at a certain day, which you shall make known to them, they attend to this with you, in form aforesaid. Witness, Edmund Earl of Cornwall, at Westminster, on the 26th day of May."

Report to Her Majesty's Principal Secretary of State for the Home Department, from the Poor Law Commissioners on an inquiry into the Sanitary Condition of the labouring population of Great Britain, 1842 